\title{
A SEGURANÇA COMO SINÔNIMO DE INCERTEZA: A IMPORTÂNCIA DO JUDICIÁRIO NOS MODELOS DE GOVERNANÇA ELEITORAL LATINO-AMERICANOS
}

\author{
The legal certainty as synonym uncertanty: the relevance of the Judiciary in Latin \\ American electoral governance models
}

Felipe Gallo da Franca

Resumo: O presente artigo visa a apresentar o paradoxo existente entre a governança eleitoral e a segurança jurídica. Através de uma análise conceitual da segurança jurídica, aduzimos a existência de novas definições que extrapolam o aspecto da previsibilidade. Além disso, apontamos para a expansão do protagonismo judicial do modelo de governança eleitoral latino-americano, que, além de garantir a integridade, também incentivou a incerteza do resultado eleitoral. Portanto, pretendemos responder a seguinte questão: como definir a segurança em um ambiente que impera a incerteza?

Palavras-chave: Segurança jurídica. Governança eleitoral. América Latina.

\begin{abstract}
The present article aims to the paradox between electoral governance and legal certainty. Through a conceptual analysis of legal certainty, we present the existence of new definitions that extrapolate the classic aspect of predictability. On the other hand, we point to the expansion of the judicial protagonism in the Latin American electoral governance model, which, in addition to ensuring integrity, also encouraged the uncertainty of the electoral result. Therefore, we want to answer the following question: how to define certainty in an uncertain environment?
\end{abstract}

Keywords: Legal certainty. Electoral governance. Latin American.

Artigo recebido em 3 dez. 2018 e aprovado em 26 ago. 2019. 


\section{Introdução}

A eleição é um momento único na experiência democrática de distintas sociedades. Ainda que a ciência do direito e demais campos do conhecimento compreendam que o exercício democrático não se encerra nela, é nas eleições que os cidadãos elegem seus representes para exercerem mandatos no decorrer das respectivas legislaturas.

A centralidade das eleições como campo de análise permitiu uma série de estudos que abordam o fenômeno sob distintos olhares. No campo do Direito e da Ciência Política, os estudos, entretanto, priorizaram a análise dos sistemas eleitorais e da função judicante do Tribunal Superior Eleitoral e do Supremo Tribunal Federal. Ainda que imprescindíveis para o debate, poucos estudos analisam a importância da governança eleitoral como sistema garantidor da lisura e da segurança jurídica dos pleitos.

Nosso estudo pretende abordar exatamente essa seara, enxergando como o sistema de governança ganhou contornos de extrema importância na consolidação da democracia na América Latina ao garantir uma função de destaque ao poder judiciário. Pretendemos abordar essa perspectiva pelo viés da segurança jurídica, pois, no campo de estudos eleitoral, tal instituto se apresenta paradoxalmente.

O conceito clássico de segurança jurídica preconiza a previsibilidade, enquanto uma eleição somente pode ser considerada válida se existir uma dose de imprevisibilidade, pela qual todos participantes possuem chances de serem eleitos. $\mathrm{O}$ resultado, assim, não pode ser consolidado de antemão, sob pena de se retirar o caráter democrático das eleições. Portanto, a segurança jurídica adquire novos contornos se vislumbrada perante a governança eleitoral.

Debateremos, assim, as diferentes concepções de segurança jurídica trabalhadas atualmente pela literatura jurídica. Posteriormente, apresentaremos o contexto político latino-americano e como o modelo de governança eleitoral de seus países conferiu um protagonismo cada vez mais crescente ao poder judiciário. Por fim, finalizaremos o ensaio, buscando responder o paradoxo: como garantir a segurança em um ambiente de incertezas. 


\section{A segurança jurídica}

A segurança jurídica, originalmente ou de forma bastante difundida entre teóricos, costuma ser trabalhada na ótica da previsibilidade. Isto é, as leis devem ser claras o suficiente para que o intérprete alcance resultados esperados. Ainda que existam princípios e standards passíveis de interpretações distintas sob os olhares dos magistrados, as decisões precisam ser coerentes com a coletividade de órgãos julgadores, fornecendo decisões que garantam segurança ao jurisdicionado.

Nesse sentido, clássicos são os ensinamentos de José Afonso da Silva (2007, p. 17), que desdobra o conceito de segurança sob dois aspectos. A segurança do direito pressupõe a positividade, enquanto a segurança jurídica seria a realização prática dessa positividade. Assim, a segurança, para além de ser adjetivada como sinônimo de previsibilidade, certeza e proteção, precisa ter implicações concretas na vida dos jurisdicionados, que passam a saber de antemão as consequências jurídicas de seus negócios e atos praticados.

Tal definição, ao nosso ver, contém apenas um campo de aplicação do conceito de segurança jurídica, pois é bem verdade que ela compreende um espectro ainda maior. Entendemos que a segurança jurídica, tal qual é trabalhada, abrange apenas o processo decisório e a consequente aplicação das leis no seio social.

Outros autores trabalham a segurança jurídica em um viés político-histórico, em que relacionam as tensões existentes entre a concessão e as retiradas de direitos no decorrer das relações políticas ao longo da história. Isto é, como uma garantia de que os preceitos institucionais e constitucionais se moldem para salvaguardar o indivíduo contra a retirada de direitos sociais, humanos e econômicos. Nessa linha, enquanto Cerqueira (2007, pp. 41-43) se debruça sobre os adventos do neoliberalismo e suas implicações perante o estado do bem-estar social, Piovesan e Ikawa (2007, pp. 48-78) se preocupam com a flexibilização de direitos sociais, vistos pelas autoras como marcos de conquistas históricas em um plano internacional de defesa dos direitos humanos.

Sob um pano de fundo semelhante, Sarlet (2007, p. 87-88) apresenta que o conceito de segurança jurídica é multifacetário, mas se ocupa de analisar a eficácia e a efetividade dos direitos. Dialogando com a "doutrina constitucional contemporânea" (SARLET, 2007, p. 90), o autor reflete que a segurança jurídica se apresenta como “expressão inarredável do Estado 
de Direito", o que preconiza o reconhecimento de direitos invioláveis, dos quais não se pode permitir um retrocesso.

Contudo, a segurança jurídica também pode ser apresentada sob uma perspectiva sociopolítica, ou seja, pela confiança que a sociedade deposita em suas instituições, em um processo de legitimação democrática. Logo, o cidadão não deve apenas se sentir seguro quanto à previsibilidade de que a norma será interpretada conforme suas expectativas, mas também que, ao serem aplicadas, as instituições responsáveis por sua execução estejam imbuídas de confiança e legitimidade.

Nesse sentido, José Rodrigo Rodriguez (2012, p. 129-152) alcança seu conceito de segurança jurídica. Ao fugir da visão textualista (de que o texto da lei é capaz de dar uma resposta única e exclusiva), aduz que tal conceito deve ser apresentado em um viés argumentativo, pelo qual a centralidade do debate afasta aplicações autoritárias e arbitrárias do direito.

A jurisprudência, nesse sentido, passa a ser valorizada como um mecanismo pelo qual tal debate pode ser propiciado. Todas as distintas posições e visões dentro do direito disputam um espaço de debate para que se alcance um acordo quanto à predominância de determinada concepção em um procedimento de tomada de decisão. Assim, as distintas perspectivas compõem um processo de constante debate, sendo que o fator fundamental para que tal processo se dê em um espectro de segurança jurídica repouse na legitimidade de um sistema criado para garantir a melhor decisão conforme o contexto (RODRIGUEZ, 2012, p. 134).

O conceito de segurança jurídica apresentado por Rodriguez (2012, p. 129-152), traz novos contornos sobre o debate acerca do tema, especialmente por apresentar que é possível garantir a segurança jurídica em um ambiente de incerteza desde que o processo decisório seja legítimo.

Dessa forma, sem querer esgotar a temática e após as reflexões trazidas pelos autores citados, conseguimos apresentar um conceito sobre o que entendemos por segurança jurídica. Nesse sentido, trata-se de uma visão lato, que definimos como um conceito multifacetário, o qual, por sua vez, engloba a proteção de direitos, legitimamente definidos em um processo de decisão democrático, em diferentes esferas, sociais e políticas, que visem, em última instância, garantir a fruição dos direitos humanos. Por outro lado, a segurança jurídica stricto sensu relaciona-se com o processo de decisão judicial, pelo qual o julgador deve garantir a previsibilidade e a cer- 
teza dos atos praticados pelos jurisdicionado, desde que tal decisão se dê em um contexto de debate jurídico, legitimado por diferentes visões jurídicas sobre um mesmo fenômeno, com a garantia de que, ao final do processo, seja alcançada uma deliberação que responda o caso concreto da melhor forma possível.

\section{A governança eleitoral como marco de estudo}

Ainda que imprescindíveis para o debate, poucos estudos analisam a importância da governança eleitoral como sistema garantidor da lisura e da segurança jurídica dos pleitos (ELKLIT, REYNOLDS, 2000, p. 4); (SCHEDLER, 2001, p. 181). O interesse acadêmico sobre a temática evidenciou que a "a governança eleitoral importa" (MOZAFFAR; SCHEDLER, 2002, p. 5), apresentando resultados substantivos de sua relevância sobre a qualidade e confiabilidade das eleições (MEDINACELI; TORRES, 2017, p. 13). Um dos turning points para a centralidade da governança em estudos internacionais mais recentes (HARTLYN; MCCOY; MUSTILLO, 2008, p. 74) foi a controvérsia da eleição presidencial norte americana de 2000. O episódio registrou que, mesmo países com regimes democráticos consolidados podem gerar desconfiança da lisura do pleito caso existam problemas com a administração das eleições.

A governança eleitoral pode ser entendida como uma interação constitucional, legal e institucional, cujas regras, normas e princípios se refletem no procedimento eleitoral e na competitividade de seus participantes (HARTLYN; MCCOY; MUSTILLO, 2008, p. 74). Dessa forma, ela cria e estrutura as regras que servirão para balizar as eleições (MOZAFFAR; SCHEDLER, 2002, p. 7), compreendendo três fases distintas: rule making, rule administration e rule adjudication (MARCHET'TI, 2008, p. 867). Isto é, a governança dimensiona os atores e instituições que serão responsáveis pela elaboração de regras, leis e resoluções que moldarão o processo eleitoral (rule making). As instituições e atores são responsáveis pela implementação das normas, pela gestão da eleição e pela fiscalização dos participantes (rule administration); e também responsáveis pelo julgamento de eventuais contendas que existirem durante o pleito (rule adjudication).

A classificação tripartite, porém, muitas vezes não reflete a atual configuração institucional de muitas democracias. Alguns autores compreendem que a governança eleitoral não deve ser apresentada como uma 
análise institucional hermeticamente fechada, na qual nos debruçamos apenas no estudo das instituições que compõem aquele sistema. Ainda que determinada democracia possua instituições fortes e bem delineadas, trais atributos são vistos como secundários, caso o país enfrente momentos de turbulência democrática (ALVAREZ, 2009, p. 68). Por isso, para além de uma visão institucionalista, a governança eleitoral se envolve em uma compreensão do "contexto" (LÉON, 2009, p. 98), isto é, o conjunto de relações em um determinado desenho institucional e sua relação com atores sociais, como eleitores, imprensa e sociedade civil.

O enunciado, conforme apontado por Barreto (2016, p. 191), é "neutro", o que implica reconhecer que ele poderia ser utilizado em qualquer acepção de processo eleitoral. Ao descrever apenas os mecanismos e as instituições que permitem a realização de um pleito, o conceito não se debruça sobre questões essenciais como a legitimidade dos mandatos eletivos e pressupostos democráticos do sistema político-partidário em que se encontra. Se, por um lado, a legitimidade e a lisura do processo eleitoral garantem que o voto seja livre, existem elementos exógenos à governança eleitoral que podem auxiliar na manutenção de regimes autoritários ou abusivos. Por tais motivos, a governança eleitoral, por si só, não é capaz de mensurar a qualidade e o desenvolvimento democrático de determinado país, ainda que seja um instrumento essencial para sua constatação.

Ainda assim, a compreensão institucionalista da governança eleitoral nos permite uma abordagem didática ao definir quais são as principais funções atribuídas às instituições durante as eleições, motivo pelo qual continuaremos a adotá-la ao longo desse artigo.

Para além da distinção de suas respectivas fases, a literatura também se ocupou de classificar os principais institutos que as compõem, facilitando, assim, a realização de estudos comparados. Dessa forma, os institutos responsáveis pela fase rule administration tendem a ser denominados como EMBs (Electoral Managment Bodies), enquanto a fase de rule adjudication o foi como EDRBs (Electoral Dispute-Resolution Bodies) (OROZCO-HENRÍQUEZ, 2010, p. 10).

As pesquisas sobre a governança eleitoral e seus institutos, ainda que incipientes, passaram por três fases, permitindo que chegássemos a algumas conclusões sobre a temática. A primeira fase procurou compreender a relação entre a administração eleitoral com o processo de democratização de países que saíram recentemente de conflitos armados, analisando, assim, 
o impacto e a autoridade das EMBs nesse processo; a segunda fase procurou compreender e classificar as distintas fases da governança, com o fito de encontrar padrões institucionais e posteriormente compará-los; por fim, a terceira fase compreende a análise das funções exercidas pelos EMBs e EDRBs e o possível conflito de competências entre órgãos administrativos e judiciais durante as campanhas eleitorais.

\subsection{O contexto latino americano e a judicialização da gover- nança eleitoral}

Diante de quadros de instabilidade social e política existem duas formas de se resolver os conflitos decorrentes desse contexto. A forma mais primitiva, mas que ainda possui resquícios na atualidade, é a de que os conflitos políticos sejam resolvidos pelo uso da força e da violência. O embate entre estruturas militares ou paramilitares permite que os vencedores do conflito ocupem as instâncias de governo e legitimem atos em prol de seu grupo político (LEHOUCQ, 2002, p. 36). Naturalmente tal forma não é a mais recomendada para a resolução de conflitos sociais, pois a violência pode resultar em uma maior instabilidade política, especialmente pela suspensão de direitos políticos da parcela que se opõem aos vencedores. A segunda solução encontrada seria retirar a gestão do conflito das partes envolvidas, nomeando um terceiro, independente e autônomo, para gerenciar o litígio (LEHOUCQ, 2002, p. 36).

Nesse sentido, é importante compreender o modelo de governança eleitoral como salvaguarda para que as eleições se apresentem como justas e livres, garantindo credibilidade ao processo (OROZCO-HENRÍQUEZ, 2010, p. 20). Garantir um modelo bem consolidado não significa que as eleições serão necessariamente genuínas, mas a ausência deste parâmetro pode agravar potenciais conflitos políticos e ir de encontro à integridade do pleito, especialmente na ocorrência de eventuais impugnações ou questionamentos sobre a lisura das eleições. Tais casos são comuns de ocorrem em qualquer processo de disputa eleitoral e demandam respostas institucionais satisfatórias para corroborarem o sentimento de confiança pelo pleito (OROZCO-HENRÍQUEZ, 2010, p. 20-21).

As autoridades eleitorais devem ser apresentadas aos participantes como capazes de dirimir os conflitos existentes antes e depois das votações. Algumas das características esperadas dessas instituições seriam a imparcialidade e a capacidade de produzir resultados eficazes assim que proferidas as decisões (ALVAREZ, 2009, p. 62). 
Lehoucq (2002, p. 36) advoga pela necessidade de instituições de controle eleitoral despolitizadas e, por isso, independentes dos poderes executivos e legislativos. A delegação da função julgadora para um órgão neutro evitaria disputas políticas entre os poderes e afastaria uma suposta desconfiança da sociedade com o modelo de governança.

A hipótese do autor é a de que o modelo clássico da governança, autorregulação partidária (ou seja, os próprios partidos se governam), permitiu e induziu uma série de conflitos políticos ao longo da história latino-americana (ou mesmo estadunidense). Nesse sentido, quando as estruturas de governança permitiram que o poder fosse delegado a um terceiro, independente e apartidário, os conflitos foram amenizados (LEHOUCQ, 2002, p. 38).

Diante da ausência de parcialidade dos julgadores políticos em promover um ambiente neutro de governança, o ator majoritariamente escolhido para exercer a função de julgar os pleitos na américa latina foi o poder judiciário (LEHOUCQ, 2002, p. 38). Diversos autores refletem que o modelo latino americano trouxe um novo paradigma de confiabilidade e segurança para os processos eleitorais (LEHOUCQ, 2002, p. 42). Ainda que tal contribuição tenha sido renegada por uma literatura mais vasta, cientistas políticos e juristas apresentam que o poder judiciário tende a ganhar funções de maior destaque em reformas mais recentes dos modelos de governança eleitoral ao redor do mundo (LEHOUCQ, 2002, p. 42).

Diante desse protagonismo crescente que o judiciário vem assumindo nos modelos de governança eleitoral, cabe indagar algumas das características dessa escolha e considerações críticas sobre sua implementação. De forma geral, um poder judiciário forte e independente tende a garantir benefícios à democracia, através da imposição do império da lei e da proteção de garantias e direitos individuais (GIBLER; RANDAZZO, 2011, p. 696).

O problema é definir o que seria essa "independência" proclamada pelos especialistas. Ademais, no momento em que se centralizam as atribuições do poder judiciário no exercício de controle dos atos do executivo, não se sabe qual o limite para que esse poder ou mesmo outros, caminhem em prol de um maior autoritarismo. Contudo, ao mesmo tempo, o órgão deve possuir competências suficientes para apresentar respostas institucionais a eventuais atos que visem retirar a legitimidade das eleições. 
Alvárez (2009, p. 61-76) pondera exatamente essa questão, ao analisar a função exercida pelo Consejo Nacional Electoral como órgão judicante das eleições venezuelanas. A grande crítica apontada foi a falta de capacidade institucional do órgão em reverter eleições maculadas por processos de fraude e outras ilicitudes eleitorais. Desse modo, conclui que o primeiro aspecto que deve ser analisado sob uma instituição eleitoral é o contexto político pelo qual se encontra, pois, ainda que seja considerado formalmente independente e se transpareça como uma instituição sólida e autônoma, ela, na prática, pode apresentar resultados diametralmente opostos caso não se encontre em uma democracia plena (ALVAREZ, 2009, p. 62).

A ambivalência de seus sentidos e o protagonismo como garantidor de um processo justo retiram uma função meramente procedimental do órgão julgador, visto que suas decisões e atitudes impactam diretamente os demais agentes políticos e interessados no pleito (OROZCO-HENRÍQUEZ, 2010, p. 21). Esse intercâmbio de relações institucionais e sociais torna um EDRB um importante ator na modelagem das relações político-eleitorais, mas também passível de ser moldado conforme o contexto sociocultural e político pelo qual atua (OROZCO-HENRÍQUEZ, 2010, p. 21).

Alguns autores, inclusive, argumentam que o desenvolvimento político da América Latina está intimamente ligado à criação de ERDBs responsáveis pelo julgamento e fiscalização do processo eleitoral (LEHOUCQ, 2002, p. 31). A delegação de algumas funções administrativas e de controle dos pleitos pode ser apontada como uma das responsáveis por eliminar conflitos que ocorriam nos países latino-americanos (FLEICHER; BARRETO, 2009, p. 127); (BALLIVIAN, 2009, p. 78); (ALVAREZ, 2009, p. 65); (FLEICHER; BARRETO, 2009, p. 118). Com a resolução pacífica e célere dessas irregularidades, Lehoucq (2002, p. 31) aponta que o resultado imediato foi o aumento dos índices de confiança social e, consequentemente, um incentivo para se engajar no ambiente público.

Atribuições administrativas e regulatórias foram gradualmente sendo implementadas em órgãos originalmente posicionados como EDRBs. Na Bolívia, a Corte Nacional Electoral (CNE) foi criada como um órgão independente do poder executivo, responsável pela gestão do processo eleitoral e resolução dos conflitos (BALLIVIAN, 2009, p. 78). Na Costa Rica, o Tribunal Superior Electoral (TSE) possui não apenas semelhanças com o nome do EDRB brasileiro, mas especialmente na consecução de suas funções, por ser responsável por expedir resoluções, administrar o pleito e julgar as contendas decorrentes do processo eleitoral (LEÓN, 2009, p. 96). 
Ainda assim persistia um certo ceticismo inicial na capacidade de alguns EDRBs latino-americanos em modificar práticas corruptas dos atores políticos. Nesse cenário, Ballivian (2009, p. 79-80) reflete que, mesmo que a implementação da Corte Nacional Electoral (CNE) tenha se apresentado como um sucesso institucional na Bolívia, ela pouco contribuiu para que os atores políticos deixassem de praticar ilicitudes eleitorais, especialmente pela ausência de mecanismos que oportunizassem que os órgãos eleitorais pudessem reverter os resultados das urnas diante de potenciais fraudes (BALLIVIAN, 2009, p. 84). No caso boliviano, as pressões políticas tendiam a indicar os vocales, autoridades que compunham a CNE, de modo a exercer controle político sob seus indicados e perpetuar a força política de grupos ligados ao governo (BALLIVIAN, 2009, p. 78).

Tal exemplo revela que um órgão de controle deve ser isento e independente do controle das forças políticas, mas, ao mesmo tempo, para que tais órgãos possuam relevância e possam exercitar o poder de controle que a eles foi incumbido, devem possuir poderes suficientes para sopesar as manipulações ou tentativas de burlar o controle eleitoral. Foi apenas depois de uma série de sucessivas reformas institucionais que o órgão de controle boliviano passou a adquirir autonomia política de seus jurisdicionados. Em conjunto com a implementação da tecnologia nos pleitos e campanhas educativas aos eleitores, o CNE alcançou níveis satisfatórios de independência e confiabilidade (BALLIVIAN, 2009, p. 87). O caso da Bolívia também pode ser apontado como emblemático, pois após garantir uma certa estabilidade na condução das eleições, o CNE adquiriu cada vez mais funções institucionais de controle da burocracia eleitoral e partidária, especialmente pela possibilidade de resolver conflitos interna corporis de partidos políticos, controlar os gastos de campanha e fiscalizar os recursos públicos subvencionados aos políticos (BALLIVIAN, 2009, p. 88). Tal fenômeno parece ter se espraiado para outros EDRBs latino-americanos que tendem a regular cada vez mais a vida político-partidária.

Em 1990, após um período eleitoral conturbado ocorrido dois anos antes, o México passou por reformas institucionais que reforçaram a perspectiva de seus ERDBs e EBMs. Os reformadores mexicanos apresentaram quatro estratégias principais: 1) maior regulação da atividade político eleitoral; 2) delegação da gestão das eleições para uma entidade independente do governo, o IFE (Instituto Federal Electoral); 3) submissão dos comícios eleitorais a uma supervisão maior pelos órgãos de controle; e 4) 
implementação de um EDRB, o Tribunal Electoral del Poder Judiciário Federal, transferindo a resolução de conflitos eleitorais da Câmara dos deputados para um órgão do poder judiciário (SCHEDLER, 2009, p. 48-49).

Após uma reforma legislativa em 2014, as atribuições do Tribunal Electoral del Poder Judiciario foram reformuladas, substituindo um modelo de controle regionalizado e dependente de órgãos do Poder Executivo local (TORRES, 2016, p. 26) por um duplo âmbito de controle jurisdicional: um juízo nacional para as eleições federais e outro "subnacional" para as eleições regionais (TORRES, 2016, p. 26).

Dentre as atribuições deste Tribunal, criado em 1996, encontra-se o exercício da jurisdição especializada em contendas eleitorais de âmbito nacional durante o referido período, sendo responsável pela definição de jurisprudência que balizará os entendimentos dos tribunais subnacionais para as eleições vindouras (TORRES, 2016, p. 28) e a correta adequação dos atos e resoluções expedidos pelas autoridades eleitorais aos princípios constitucionais e legais estabelecidos (DE LOS REYES; GUEVARA, 2018, p. 227). A referida reforma ainda introduziu uma câmara sancionadora para os atos de abuso eventualmente cometidos pelos atores políticos, especialmente aqueles que protagonizaram irregularidades quanto ao exercício da comunicação política. Por fim, instituiu o Código Nacional Electoral, responsável por nacionalizar o regramento legislativo eleitoral mexicano, culminando em uma maior relevância das decisões emanadas de seus respectivos órgãos jurisdicionais (TORRES, 2016, p. 26).

No caso brasileiro, a justiça eleitoral se apresentou como um case de sucesso por três motivos (FLEICHER; BARRETO, 2009, p. 118): (1) centralização da gestão eleitoral em um órgão nacional, afastando o intento abusivo de elites locais; (2) neutralidade e independência, pelo fato do órgão estar vinculado ao poder judiciário; e (3) a melhoria de procedimentos eleitorais através de inovações tecnológicas. Dessa forma, o judiciário conseguiu se consolidar como um poder independente, capaz de fornecer respostas institucionais céleres e eficientes frente a eventuais abusos.

Portanto, interessante traçar algumas características comuns dos EDRBs latino americanos. Além de uma presença cada vez mais constante do poder judiciário, tais democracias buscaram maximizar a regulação da seara político-eleitoral, impedindo que os agentes políticos atuassem com maior liberdade (OROZCO-HENRÍQUEZ, 2010, p. 73). As escolhas político-institucionais para a instituição de um modelo de governança eleitoral Resenha Eleitoral (Florianópolis), v. 22, n. 1-2, p. 127-144, 2018 
bem-sucedido dependem de fatores políticos e históricos, próprios do contexto local de cada país. Tal conclusão nos remonta à impossibilidade de existir um modelo universalista que consiga gerir, regular e julgar as eleições com a mesma eficiência em diferentes regiões do mundo. Contudo, um fator que pode ser apontado como essencial, para qualquer modelo, é que os cidadãos se encontrem em pleno gozo dos seus direitos políticos.

A instalação e a manutenção de regimes autoritários, ou mesmo a existência de atitudes autoritárias que convivem de maneira mais sútil com regimes democráticos, enfraquecem o potencial de ação protagonizado por um EDRB. Em razão da relativização de preceitos constitucionais e o eventual aumento da violência como modo de se resolver conflitos políticos, a exequibilidade das decisões proferidas por um EDRB tendem a ser renegadas por aqueles que descumprirem as normas (OROZCO-HENRÍQUEZ, 2010, p. 42). Ademais, o uso de uma estratégia de comunicação política que vise deslegitimar os institutos eleitorais pode reverberar para os EDRBs, que em eventuais decisões desfavoráveis a candidaturas autoritárias podem ter sua credibilidade esfacelada e deslegitimada perante a sociedade.

O essencial para que um EDRB consiga atuar com êxito em prol de se garantirem eleições justas e limpas repousa no desenvolvimento de uma cultura política e democrática, que deposita confiança na capacidade do EDRB cumprir com suas tarefas (OROZCO-HENRÍQUEZ, 2010, p. 42).

\subsection{Entre a cruz e a espada: como definir a segurança em um ambiente em que reina incerteza?}

A democracia pressupõe a possibilidade de mudanças e transições. A hipótese de que determinado projeto político que antes se encontrava na oposição seja sagrado vencedor das urnas deve ser encarado com certa naturalidade. As eleições são um momento de naturais incertezas, pois ainda que as condições fáticas e políticas apontem para alguns favoritos, a rigor todos os competidores devem possuir chances, mesmo remotas, de se sagrarem vencedores. Nesse sentido, diante de uma probabilidade de mudança, a democracia se aperfeiçoa durante as eleições quando garante uma transição pacífica entre governos (AAKEN, 2009, p. 297).

Nesse sentido, um aparente paradoxo pode ser apontado. Pois, como vimos anteriormente, a segurança jurídica é essencial para se garantir um processo eleitoral íntegro. Em sua visão clássica, o conceito de segurança jurídica, como retratado, apresenta-se como sinônimo de certeza e 
previsibilidade. Por outro lado, a incerteza não é apenas natural em um processo eleitoral, mas legitima o próprio aspecto democrático em um escrutínio. Contudo, o avançar das discussões sobre a segurança jurídica e a governança eleitoral parece ter respondido tal paradoxo.

As instituições eleitorais estão vinculadas com a implementação de "políticas públicas eleitorais", cujo objetivo é "organizar a incerteza eleitoral promovendo certeza institucional” (MOZAFFAR; SCHEDLER, 2002, p. 11). Tal ambivalência se reflete diante da incerteza em se reconhecer de antemão o vencedor das urnas, paralelamente ao sucesso no âmbito institucional, pelo qual se visa garantir segurança técnica e legitimidade democrática do resultado do pleito (MEDINACELI; TORRES, 2017, p. 13); (AAKEN, 2009 p. 303). Portanto, um modelo de governança eleitoral bem estruturado garante a perpetuação da incerteza dos resultados dos votos, mas mitiga as incertezas relacionadas à qualidade das instituições eleitorais e das respostas dadas por ela à sociedade.

Nesse sentido, os principais objetivos de um sistema de governança eleitoral, seriam: (1) promover a eficiência administrativa; (2) apresentar neutralidade perante os conflitos políticos; e (3) prestar contas dos candidatos e de suas instituições aos eleitores (BARRETO, 2016, p. 192-193).

Conforme exposto, no contexto latino-americano, diante da existência de irregularidades, percebeu-se que as instituições eleitorais deveriam ser centralizadas em um órgão neutro.

Um histórico de fraudes eleitorais gera uma expectativa de que tais fraudes ocorrerão nos próximos pleitos. Diante desse cenário, a sociedade, desconfiada de seus quadros políticos, tende a clamar por reformas que retirem a discricionariedade de atuação dos mesmos. O que culmina no potencial reforço de instituições eleitorais e de outros aparatos burocráticos. A desconfiança, assim, ainda que podendo culminar em alguns efeitos deletérios, também se tornou essencial para o fortalecimento das próprias instituições (SCHEDLER, 2001, p. 189).

O perigo, porém, repousa na zona cinzenta, pois quadros de desconfiança podem apontar para duas direções distintas: (1) pleitear que as novas eleições sejam cada vez mais seguras, reforçando mecanismos de controle e accountability dos órgãos eleitorais; ou (2) desacreditar na própria democracia, reforçando um sentimento de inutilidade das eleições que pode culminar em guinadas autoritárias (SCHEDLER, 2001, p. 189). 
A ausência de credibilidade dessas instituições perante a sociedade fomenta a desconfiança não apenas no processo em questão, mas espraia-se sobre todo o processo democrático e na confiabilidade da política como resolução de conflitos. Assim, os eleitores passam a questionar a importância do voto ou mesmo concluir naturalmente que os processos são fraudulentos (SOLIJONOV, 2016, p. 11).

É nesse cenário que possamos nos debruçar sobre a relação entre segurança jurídica com governança eleitoral.

A concepção lato sensu da segurança jurídica define-se como a salvaguarda do Estado de Direito e a proteção da integridade das relações sociais com as instituições estatais. Dessa forma, a segurança das eleições baliza o processo eleitoral de eventuais pressões políticas advindas de grupos de interesse que buscam macular o pleito para garantir a perpetuação de determinadas estruturas de poder (MANIN; PRZEWORSKI; STOKES, 2006, p. 107); (ONISHI, 2012, p. 66).

Nesse mesmo âmbito, a legitimidade se apresenta como instrumento central da garantia de processos eleitorais íntegros.

O processo eleitoral preconiza a existência de fatores suficientes para considerar determinada situação como em um plano de normalidade democrática, no qual a sociedade civil e a imprensa possam agir com certo grau de liberdade (BIRCH; VAN HAM, 2017, p. 491) e a comunicação política impere da mesma forma. Ainda que a situação de jure das instituições eleitorais pareça satisfatória com padrões internacionais de accountability e de gestão administrativa, ressaltamos que eleições íntegras somente podem ser perquiridas após a análise da situação de facto das eleições (BIRCH; VAN HAM, 2017, p. 498).

Contudo, a segurança jurídica em seu sentido stricto também se apresenta de fundamental importância. Ainda que as incertezas sejam naturais, as instituições eleitorais devem apresentar respostas contundentes e precisas à sociedade.

Uma eleição desprovida de erros é improvável que aconteça. Qualquer processo complexo como a gestão de um pleito é passível de erros. Conforme apresenta Aaken (2009, p. 303), os efeitos que uma deficiência técnica pode causar, como impulsionadora de uma desconfiança dos eleitores com as instituições eleitorais, independem do grau de amadurecimento democrático de determinados países. 
Qualquer irregularidade administrativa ou de desconfiança com as instituições ou os agentes eleitorais possui o condão de agravar a confiança da sociedade e dos candidatos do processo eleitoral como um todo (SCHEDLER, 2009, p. 47). Por esse motivo, precisam apresentar resultados consistentes, que refletem a capacidade das instituições eleitorais de gerir um processo eleitoral com eficiência administrativa e munidas de instrumentos tecnológicos que impulsionem o sentimento de confiança do eleitorado (CARTER; FARRELL, 2010, p. 20); (SOLIJONOV, 2016, p. 9).

A certeza, portanto, é apresentada pelo devido funcionamento das instituições, tanto em âmbito administrativo quanto judicial, pelos quais as decisões devem ser apresentadas em um escopo de confiabilidade e legitimidade, com o fito de garantir a previsibilidade de um resultado íntegro.

\section{Considerações finais}

Após esse breve ensaio, conseguimos apresentar algumas conclusões preliminares sobre a noção da segurança jurídica sob o marco de estudo das eleições. Tais considerações, porém, não visam esgotar a temática, mas instigar o aprofundamento dos estudos nessa seara, especialmente diante das consequências normativas e políticas que podemos extrair delas.

Em um primeiro momento, foi possível vislumbrar que a América Latina trouxe uma importante contribuição para os estudos da governança eleitoral ao apresentar o judiciário como agente capaz de resolver o sentimento de insegurança da sociedade com as instituições eleitorais. Ainda que a expansão da judicialização no modelo de governança eleitoral deva ser analisado com precaução, ela trouxe resultados satisfatórios na confiança social, com as instituições eleitorais da América Latina.

A confiança nas eleições e a gestão de processos íntegros exponencializam a incerteza dos resultados eleitorais. A princípio, paradoxalmente, apontamos que a incerteza é responsável por garantir a segurança jurídica das eleições. Tal frase somente faz sentido, porém, se nos afastarmos de um conceito clássico de segurança jurídica, calcado em grande parte no processo hermenêutico de previsibilidade das decisões judiciais, e se caminharmos para um conceito que apresente a legitimidade como inerente à segurança. 


\section{Referências}

AAKEN, Anne Van. Independent electoral management bodies and international election oberver missions: any impact on the observed level of democracy? A conceptual framework. Constitucional Political Economy. September, 2009, p. 296-322.

ÁLVAREZ, Ángel E. E1 Consejo Nacional Electoral y los dilemas de la competencia electoral en Venezuela. América Latina Hoy, Salamanca, 51, Ediciones Universidad de Salamanca, p. 61-76, 2009.

BALLIVIÁN, Salvador Romero. Medio siglo de historia del organismo electoral de Bolivia. América Latina Hoy, Salamanca, 51, Ediciones Universidad de Salamanca, p. 77-94, 2009.

BARRETO, Alvaro Augusto de Borba. A Justiça Eleitoral brasileira: modelo de governança eleitoral. Paraná Eleitoral. Curitiba, v. 4, n. 2, p. 189-216, 2016.

BIRCH, Sarah; VAN HAM, Carolien. Getting away with foul play? The importance of formal and informal oversight institutions for electoral integrity. European Journal of Political Research, p. 487-511, 2017.

CARTER, Elisabeth; FARRELL, David M. Electoral Systems and Election Management. In: LE DUC, Larry, NIEMI, Dick, NORRIS, Pipa (Org.) Comparing Democracies 3. Londres, Sage, p. 1-34, 2009.

CERQUEIRA, Marcello. Recado ao Tempo: Democracia e Segurança Jurídica. In: ROCHA, Cármen Lúcia Antunes (Org.). Constituição e Segurança Jurídica. Direito Adquirido, Ato Jurídico Perfeito e Coisa Julgada: estudos em homenagem a JOSÉ PAULO SEPÚLVEDA PERTENCE. Belo Horizonte: Editora Fórum, p. 31-46, 2007.

DE LOS REYES, Marco Antonio Pérez, GUEVARA, Alexander Reyes. Judicialización de las elecciones o formación de la cultura de la legalidade Electoral, dilema fundamental para la democracia mexicana. Justicia Electoral, núm. 20, vol. 1, julio-diciembre, 2018.

ELKLIT, Jørgen, REYNOLDS, Andrew. The impacto of election administration on the legitimacy of emerging democracies: a new research agenda. KELLOGG INSTITUTE: The Helen Kellogg Institute for International Studies. 2000. Disponível em: < https://kellogg.nd.edu/sites/default/ files/old_files/documents/281_0.pdf>. Acesso em: 03 dez. 2018.

FLEISCHER, David, BARRETO, Leonardo. E1 impacto de la justicia electoral sobre el sistema político brasileño. América Latina Hoy, Salamanca, 51, Ediciones Universidad de Salamanca, p. 117-138, 2009. 
GIBLER, Douglas M.; RANDAZZO, Kirk A. Testing the Effects of Independet Judiciaries on the Likelihood of Democratic Backsliding. American Journal of Political Science, Vol. 55, n. 3 Jul. 2011, p. 696-709. GRAEFF, Caroline Bianca; BARRETO, Alvaro Augusto de Borba. O modelo de governança eleitoral brasileiro e a judicialização das regras político-eleitorais. Revista Debates. Porto Alegre, v. 11, n. 1, p. 99-118, jan.-abr. 2017. HARTLYN, Jonathan, MCCOY, Jennifer, MUSTILLO, Thomas M. Electoral Governance Matters: Explaining the Quality of Elections in Contemporary Latin America. Comparative Political Studies. v. 41, n. 1, p. 73-98, 2008.

LEHOUCQ, Fabrice E. Can Parties Police Themselves? Electoral Governance and Democratization. International Political Science Review. Vol. 23, n. 1, p. 29-46, 2002.

LEÓN, Hugo Picado. Diseño y transformaciones de la gobernanza electoral en Costa Rica. América Latina Hoy, Salamanca, 51, Ediciones Universidad de Salamanca, p. 95-116, 2009.

MANIN, Bernard; PRZEWORSKI, Adam; STOKES, Susan C. Eleições e representação. Lua Nova, São Paulo, n. 67, p. 262-269, 2006.

MARCHETTI, Vitor. Governança Eleitoral: O Modelo Brasileiro de Justiça Eleitoral. Dados - Revista de Ciências Sociais, vol. 51, núm. 4, p. 865-893. Universidade do Estado do Rio de Janeiro. Rio de Janeiro, Brasil, 2008.

MEDINACELI, Julio Alejandro Ascarrunz, TORRES, Aníbal Germán. Gobernanza electoral en unidades subnacionales de Bolivia y Argentina: un análises desde los procesos de empadronamiento. Apuntes Electorales, Año XVI, núm. 57, julio-diciembre, p. 9-40, 2017.

MOZAFFAR, Shaheen, SCHEDLER, Andreas. The comparative Study of Electoral Governance - Introduction. International Political Science Review (2002), vol. 23, No. 1, 5-27.

ONISHI, Yutaka. Electoral Management Bodies and Electoral Governance. Japanese Journal of Electoral Studies. Vol. 28, n. 2, p. 62-77, 2012.

OROZCO-HENRÍQUEZ, Jesús. Electoral Justice: The International IDEA Handbook. International Institute for Democracy and Electoral Assistance, p. 1-248, 2010. Disponível em: < https://www.idea.int/>. Acesso em: 03 dez. 2018. 
PIOVESAN, Flavia; IKAWA, Daniela. Segurança Jurídica e Direitos Humanos: O Direito à Segurança de Direitos. In: ROCHA, Cármen Lúcia Antunes (Org.). Constituição e Segurança Jurídica. Direito Adquirido, Ato Jurídico Perfeito e Coisa Julgada: estudos em homenagem a JOSÉ PAULO SEPÚLVEDA PERTENCE. Belo Horizonte: Editora Fórum, p. 47-83, 2007.

RODRIGUEZ, José Rodrigo. Por um novo conceito de segurança jurídica. Racionalidade jurisdicional e estratégias legislativas. Analisi e Diritto, 2012, p. 129-152.

SARLET, Ingo Wolfgang. A Eficácia do Direito Fundamental à Segurança Jurídica: Dignidade da Pessoa Humana, Direitos Fundamentais e Proibição de Retrocesso Social no Direito Constitucional Brasileiro. In: ROCHA, Cármen Lúcia Antunes (Org.). Constituição e Segurança Jurídica. Direito Adquirido, Ato Jurídico Perfeito e Coisa Julgada: estudos em homenagem a JOSÉ PAULO SEPÚLVEDA PERTENCE. Belo Horizonte: Editora Fórum, 2007. p. 47-83.

SCHEDLER, Andreas. Distrust Breeds Bureaucracy: Democratization and the Formal Regulation of Electoral Governance in Mexico. Centro de Investigacion y Docencia Economicas. Disponível em: < https://works. bepress.com/andreas_schedler/18/>. Acesso em: 03 dez. 2018.

SCHEDLER, Andreas. Inconsistencias contaminantes: gobernación electoral y conflicto poselectoral en las elecciones presidenciales del 2006 en México. América Latina Hoy, Salamanca, 51, Ediciones Universidad de Salamanca, 2009, p. 41-59.

SILVA, José Afonso da. Constituição e Segurança Jurídica. In: ROCHA, Cármen Lúcia Antunes (Org.). Constituição e Segurança Jurídica. Direito Adquirido, Ato Jurídico Perfeito e Coisa Julgada: estudos em homenagem a JOSÉ PAULO SEPÚLVEDA PERTENCE. Belo Horizonte: Editora Fórum, 2007, p. 15-30.

SOLIJONOV, Abdurashid. Electoral Justice Regulations Around the World: Key findings from International IDEA's global research on electoral dispute-resolution Systems. International Institute for Democracy and Electoral Assistance, 2016, p. 1-70. Disponível em: <https://www.idea.int/>. Acesso em: 03 dez. 2018.

TORRES, Luis Eduardo Medina. Gobernanza y régimen Electoral en la reforma política de 2014. Primera edición, México: Tribunal Electoral del Poder Judicial de la Federación, 2016.

Felipe Gallo da Franca - Advogado e mestrando no Programa de Pós-Graduação da Faculdade de Direito da UFMG, vinculado à linha de pesquisa Poder, Cidadania e Desenvolvimento no Estado Democrático de Direito. 